\title{
Estudo morfométrico e estereológico digital da mucosa do intestino delgado de crianças eutróficas e desnutridas com diarréia persistente
}

\author{
Digital morphometric and stereologic analysis of small intestinal mucosa in well-nourished \\ and malnourished children with persistent diarrhea
}

\author{
Ana L.G. Pires ${ }^{1}$, Themis R. da Silveira² ${ }^{2}$ Vinícius D. da Silva ${ }^{3}$
}

\section{Resumo}

Objetivos: testar a hipótese de que a mucosa do intestino delgado proximal de crianças com diarréia persistente apresenta alterações morfométricas e estereológicas proporcionais ao estado nutricional, utilizando captura de imagens através de microscópio acoplado ao computador.

Métodos: estudo transversal incluindo 65 pacientes pediátricos, com idade entre quatro meses e cinco anos, com diarréia de mais de 14 dias de duração, avaliados pelos escores $\mathrm{z}$, divididos em eutróficos $=\mathrm{Z}$ $\geq 2$ DP e desnutridos $=\mathrm{z}<-2 \mathrm{DP}$; eutróficos $=\mathrm{z} \geq 2 \mathrm{DP}$, risco nutricional $=\mathrm{z}<-1 \mathrm{DP}$ e desnutridos $=\mathrm{z}<-2 \mathrm{DP}$; e de maneira contínua em ordem decrescente, utilizando-se as tabelas do NCHS. Após a captura das imagens através do programa Scion Image, foram medidas a altura dos vilos, a profundidade das criptas, a espessura da mucosa, a espessura total da mucosa e a relação vilo/cripta (100 aumentos) e a altura do enterócito, altura do núcleo e do bordo em escova (500 aumentos). A análise estereológica foi feita através de arcos ciclóides.

Resultados: para os escores z P/I, P/E e E/I, divididos em duas categorias de estado nutricional, não houve diferença estatisticamente significante quanto às medidas da altura dos vilos, profundidade das criptas, espessura da mucosa, espessura total da mucosa e relação vilo/cripta. A altura do enterócito foi a característica que apresentou maior diferença entre os grupos eutróficos e desnutridos, para os índices $\mathrm{P} / \mathrm{I}$ e P/E, em 500 aumentos, sem atingir significância estatística. No entanto, para três categorias de estado nutricional, a análise morfométrica digitalizada mostrou diferença estatisticamente significante para a relação vilo/cripta entre eutróficos e desnutridos leves e entre eutróficos e desnutridos moderados e graves $(\mathrm{p}=0,048)$. A relação vilo/cripta foi maior nos eutróficos. Através do coeficiente de correlação linear de Spearman, a altura do enterócito, a altura do núcleo do enterócito e a do bordo em escova mostraram clara associação com os índices $P / I(r=0,25 ; p=0,038)$ e $\mathrm{P} / \mathrm{E}(\mathrm{r}=0,029 ; \mathrm{p}=0,019)$. A altura do núcleo do enterócito e a do bordo em escova mostraram, ainda, associação com o índice P/E.

Conclusões: as correlações encontradas entre o estado nutricional e a morfometria das variáveis da mucosa do intestino delgado relacionaram-se ao peso dos pacientes. Embora estas associações tenham sido de magnitude fraca a moderada, há uma tendência à diminuição do tamanho do enterócito, do seu núcleo e do bordo em escova, à medida que aumenta o grau de desnutrição.

J Pediatr (Rio J) 2003;79(4):329-36: diarréia, desnutrição, morfometria digitalizada da mucosa intestinal, análise estereológica.

\section{Abstract}

Objectives: to test the hypothesis that the proximal small intestines of children with persistent diarrhea present morphometric and stereologic changes proportional to their nutritional status, using microscope images stored in a computer.

Methods: cross-sectional study with 65 pediatric patients, whose ages ranged from 4 months to 5 years, with persistent diarrhea for over 14 days. The nutritional assessment was performed according to the $\mathrm{z}$-scores for weight/age (W/A), weight/height $(\mathrm{W} / \mathrm{H})$ and height/age $(\mathrm{H} / \mathrm{A})$ ratios, divided into: well-nourished $=\mathrm{z} \geq 2 \mathrm{SD}$ and malnourished $=\mathrm{z}<2 \mathrm{SD}$; wellnourished $=\mathrm{z}>2 \mathrm{SD}$, nutritional risk $=\mathrm{z}<-1 \mathrm{SD}$ and malnourished $=\mathrm{z}<-$ 2SD; and continuously, in descending order, using the NCHS charts. After obtaining the computer images using the software Scion Image, villous height, crypt depth, mucosal thickness, total mucosal thickness, and villous/crypt ratio were measured in the fragments of the small intestinal mucosa, enlarged 100 times. When images were enlarged 500 times, enterocyte height, nuclear height and brush-border height were measured. Stereologic analysis was performed using cycloid arcs.

Results: for W/A, W/H and H/A z-scores, divided into two nutritional status categories, no statistically significant difference was observed in regard to villous height, crypt depth, mucosal thickness, total mucosal thickness and villous/crypt ratio. Enterocyte height presented the most significant difference between well-nourished and malnourished groups, for W/A and W/H ratios, with a 500x enlargement, although this difference was not statistically significant. When z-scores were subdivided into three nutritional status categories, a digital morphometric analysis showed a statistically significant difference for villous/crypt ratio between the wellnourished and slightly malnourished group and the well-nourished and mild to severe malnourished group $(\mathrm{p}=0.048)$. The villous/crypt ratio was higher among well-nourished children. Using the Spearman coefficient, the variables enterocyte height, height of enterocyte nucleus and brushborder height presented a clear association with the W/A ratio $(r=0.25$; $\mathrm{p}=0.038), \mathrm{W} / \mathrm{H}$ ratio $(\mathrm{r}=0.029 ; \mathrm{p}=0.019)$. The height of the enterocyte and the brush-border height were associated with $\mathrm{W} / \mathrm{H}$ ratio.

Conclusions: the observed associations between nutritional status and the analyzed small intestinal mucosa variables showed a positive correlation with patients' weight. Although these associations were of a slight to moderate magnitude, we observed a tendency of enterocyte size reduction, as well as a reduction in the size of its nucleus and brush-border, as the level of malnutrition increases.

J Pediatr (Rio J) 2003;79(4):329-36: diarrhea, malnutrition, digital morphometric analysis, stereologic analysis.

1. Doutora em Pediatria, Gastroenterologista pediátrica do Hospital Materno-Infantil Presidente Vargas.

2. Doutora e Professora adjunta da Universidade Federal do Rio Grande do Sul.

3. Doutor em Patologia pela Universidade Federal do Rio Grande do Sul.

Artigo submetido em 15.10.02, aceito em 22.05.03. 


\section{Introdução}

Para a Organização Mundial da Saúde, a desnutrição grave é um transtorno médico e social e está associada a $29 \%$ das mortes entre crianças de zero a quatro anos de idade $^{1}$. Pelletier e colaboradores ${ }^{2}$, no entanto, acreditam que este percentual não é expressão da realidade e consideram que 56\% das mortes na infância são devidas a danos decorrentes das formas leves de desnutrição. A patogênese da síndrome diarréia persistente associada à desnutrição é multifatorial, sendo que o desmame precoce, a pobreza, fatores infecciosos, nutricionais e fenômenos alérgicos contribuem para a sua perpetuação. O resultado final destes eventos é o dano à mucosa do intestino delgado. A compreensão das complexas interações que têm lugar na interface luminal mucosa do intestino delgado é fundamental para o entendimento da natureza desta diarréia ${ }^{3}$.

Estudos clínicos e experimentais em seres humanos evidenciam que os distúrbios nutricionais podem produzir alterações morfoestruturais na mucosa intestinal ${ }^{4,5}$. Estas alterações podem refletir-se na morfometria e na relação de superfície/volume da mucosa intestinal.

Para o estudo destas alterações, é necessário o uso de técnicas apuradas, sensíveis e que possam ser facilmente reproduzidas. Programas de computador que permitem a captura de imagens, o cálculo das dimensões, ou o número de objetos marcados pelo usuário e o armazenamento dos dados digitalmente possibilitam um estudo mais minucioso e preciso dos tecidos, entre os quais se insere o da mucosa do intestino delgado 6,7 . A captura das imagens permite a análise por outros observadores, diminui o grau de subjetividade do exame e facilita a comparação dos estudos nesta área.

O estudo morfométrico da mucosa do intestino delgado vem sendo utilizado no intuito de avaliar a intensidade das alterações encontradas em pacientes desnutridos. Alguns destes estudos mostram nítida correlação entre o estado nutricional e as alterações da mucosa do intestino delga$\mathrm{do}^{8-11}$, enquanto outros não corroboram estes achados ${ }^{3,12-15}$. No entanto, a técnica morfométrica utilizada nestas pesquisas não foi uniforme, dificultando a comparação entre os resultados obtidos. Em estudo anterior ${ }^{16}$, a análise morfométrica da mucosa do intestino delgado de 85 crianças, de quatro meses e dez anos de idade, foi realizada através de régua micrométrica, acoplada ao microscópio óptico, único método disponível na ocasião. A análise dos dados, através do coeficiente de correlação de Spearman, mostrou correlação positiva entre a altura dos vilos e o escore z P/I, a espessura total da mucosa e os escores z P/I e z P/E e entre a relação vilo/cripta e os escores z P/I e z P/E.

No estudo atual, o uso do computador permitiu a captura e o armazenamento das imagens da mucosa do intestino delgado, assim como a morfometria computadorizada de parte do material utilizado anteriormente. Neste estudo, a captura das imagens em 500 aumentos permitiu ainda realizar as medidas da altura do enterócito, da altura do núcleo e do seu bordo em escova. Para estudar as possíveis alterações na área de superfície da mucosa, foi utilizada a técnica de contagem de arcos ciclóides superpostos às imagens capturadas pelo computador.

O presente estudo visou utilizar um programa de fácil acesso, disponível na Internet (Scion Image Rasband W. Scion Image Beta 2 version on line $)^{17}$, para avaliar, por meio de morfometria computadorizada, as alterações determinadas pela desnutrição na mucosa do intestino delgado de crianças eutróficas e com diferentes graus de desnutrição.

\section{Métodos}

O material histológico foi obtido a partir dos blocos de parafina, armazenados de 85 crianças hospitalizadas, em sua maioria na Unidade de Gastroenterologia Pediátrica da Santa Casa de Misericórdia de Porto Alegre, no período de maio de 1989 a novembro de 1991. Para o presente estudo, foram selecionadas aquelas com idade entre seis meses e cinco anos, com diarréia de mais de 14 dias de duração, que realizaram biópsia de intestino delgado como parte do protocolo de investigação da diarréia. O estado nutricional foi avaliado de acordo com os escores $\mathrm{z}$ para peso/idade $(\mathrm{P} / \mathrm{I})$, peso/estatura $(\mathrm{P} / \mathrm{E})$ e estatura/idade (E/I), utilizando-se as tabelas do NCHS ${ }^{18}$. Os escores z foram divididos em duas categorias de estado nutricional (eutróficos: $z \geq 2 \mathrm{DP}$, desnutridos: $\mathrm{z}<-2 \mathrm{DP}$ ), em três categorias (eutróficos: $\mathrm{z} \geq-1 \mathrm{DP}$, com risco nutricional: $\mathrm{z}<-1 \mathrm{DP}$ a $\mathrm{z}$-2DP, e desnutridos: $\mathrm{z}<-2 \mathrm{DP}$ ) e de maneira contínua, em ordem decrescente.

O delineamento do estudo foi de corte transversal, retrospectivo. Os fragmentos de mucosa de intestino delgado foram recortados e corados com hematoxilina e eosina para estudo histológico. Foram incluídos no estudo os pacientes cujos fragmentos de mucosa de intestino delgado, cortados perpendicularmente ao eixo longitudinal do tecido, tivessem, pelo menos, seis vilos e seis criptas, para avaliação morfométrica e estereológica, obtendo-se um total de 65 fragmentos. Os novos fragmentos foram medidos por meio de régua micrométrica, como no estudo anterior. Após a captura das imagens da mucosa intestinal, realizada através do microscópio acoplado ao computador, foi feita a morfometria computadorizada para comparação entre os dois métodos. As variáveis estudadas na mucosa do intestino delgado, através de régua micrométrica e de morfometria digital, com aumento de 100 vezes, foram: a altura dos vilos, a profundidade das criptas, a espessura da mucosa, a espessura total da mucosa e a relação vilo/cripta (Figura 1). Além disso, realizou-se, nesta pesquisa, a morfometria computadorizada da altura média de, no mínimo, 30 enterócitos, dos núcleos dos enterócitos e do bordo em escova (Figura 2), com aumento de 500 vezes. As células selecionadas tinham núcleo basal e estavam localizadas no terço médio do vilo. Foi calculada a média da altura de cada variável, dividindo-se a soma das medidas pelo número de unidades observadas. Para estimar a área de superfície dos fragmentos de mucosa do intestino delgado, foi realizada, 


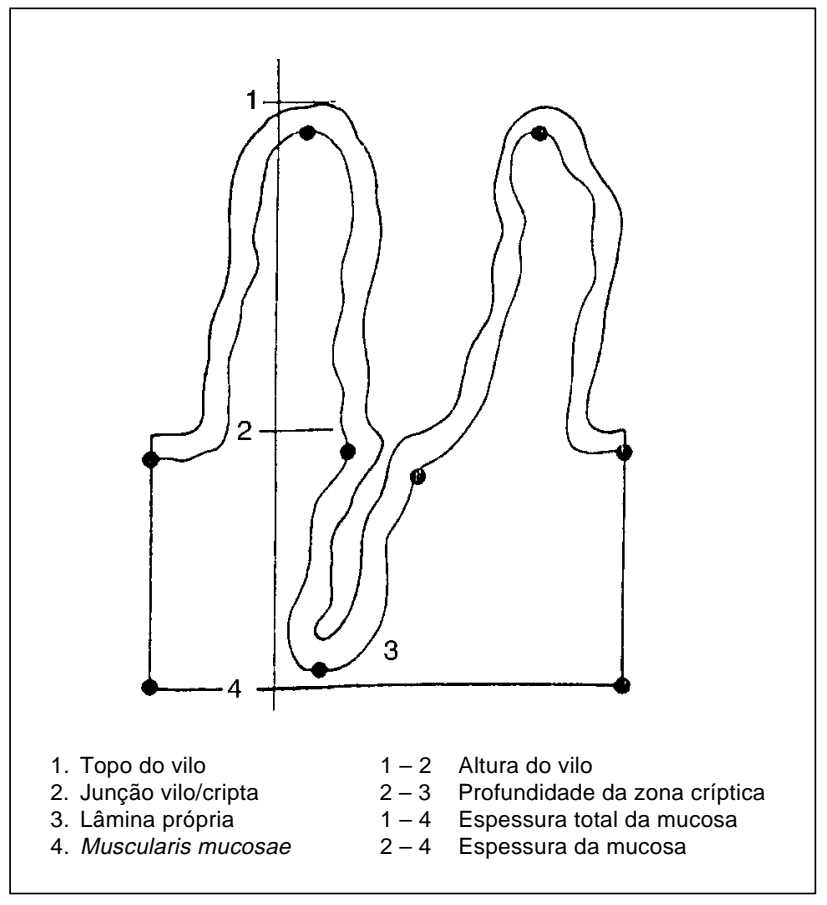

Figura 1 - Características avaliadas na mucosa do intestino delgado através de régua micrométrica e morfometria computadorizada, em 100 aumentos

ainda, a análise estereológica, por meio da contagem de arcos ciclóides, em imagens capturadas com aumento de 40 vezes (Figura 3). Para medir a área de superfície, contou-se o número de vezes que o arco ciclóide interceptava o limite da superfície epitelial, e o tecido subjacente foi avaliado pela contagem do número de pontos que caíam dentro do epitélio e da lâmina própria. $\mathrm{O}$ número resultante era um número absoluto. A estimativa da superfície foi feita através da fórmula:

$$
\mathbf{S v}=2 \cdot \frac{\mathbf{I}}{\mathbf{L}},
$$

onde $\mathbf{I}=$ interseção (soma do número de vezes em que o arco ciclóide e os pontos tocam a superfície epitelial), $\mathbf{L}=$ comprimento total das linhas de teste (é toda a grade, e é uma constante: 4,9297 mm).

A morfometria foi realizada pela primeira autora deste estudo de maneira cega quanto ao estado nutricional do paciente. Para captura das imagens da mucosa do intestino delgado, foi utilizado microscópio óptico convencional, equipado com videocâmara acoplada a microcomputador com placa de captura e programa de análise de imagens. Foram capturadas as imagens no formato tag image format. Para a análise morfométrica digitalizada, foi usado o programa Scion Image ${ }^{17}$.

Para a análise estatística, os dados quantitativos obtidos foram descritos inicialmente pela média e desvio padrão. A comparação entre dois grupos foi realizada pelo teste $t$ de Student, para amostras independentes, com estimativa de diferença média e seu intervalo de confiança (IC) de $95 \%$. $\mathrm{Na}$ consideração de três grupos, utilizou-se a análise de variância (ANOVA) de um critério de classificação, com localização de diferenças significativas pelo teste de posthoc de Student-Newman-Keuls. A avaliação de correlações lineares foi feita pelo coeficiente de correlação de Pearson (r). O nível de significância adotado foi de $\alpha=0,05$. Os dados foram processados e analisados com o auxílio dos programas SPSS, versão 10.0, e Sigma Plot v. $2.1^{19}$.

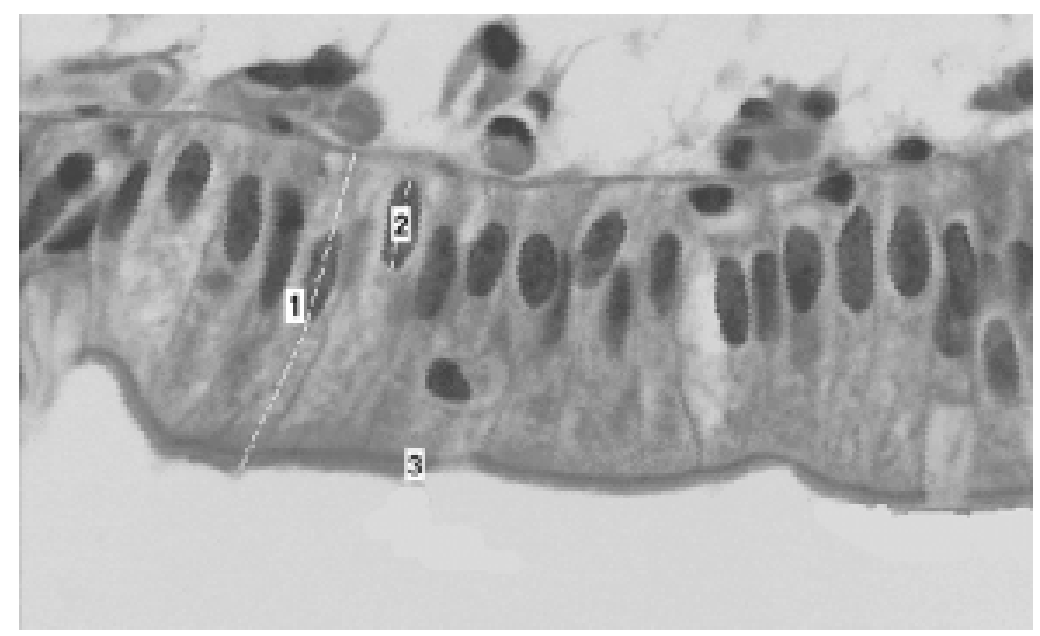

Figura 2 - Fotomicrografia da mucosa do intestino delgado, corada com HE, em 500 aumentos. Variáveis estudadas: (1) altura do enterócito, (2) altura do núcleo, (3) altura do bordo em escova 


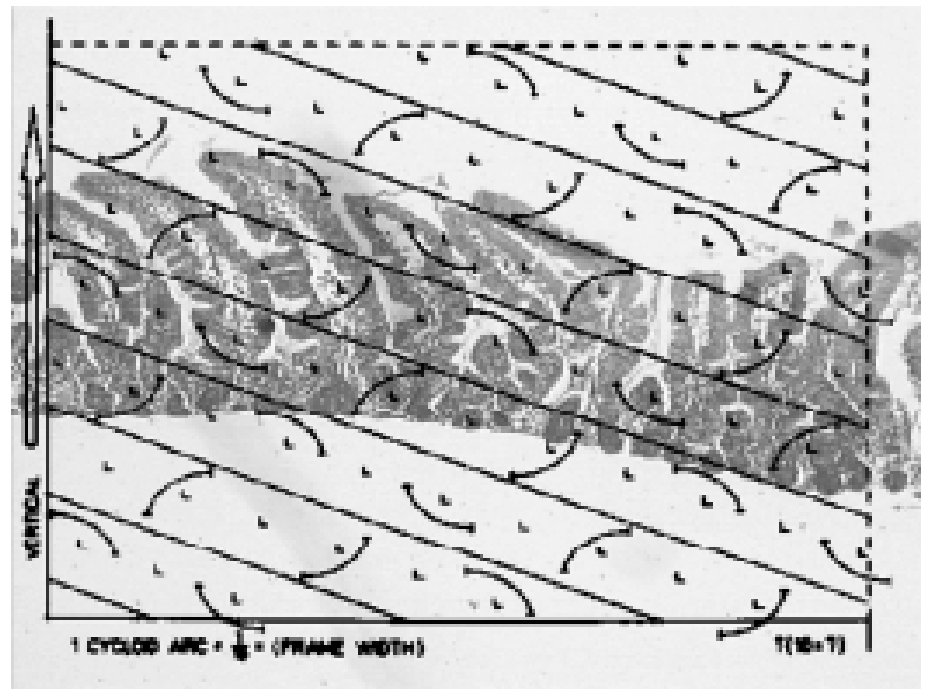

Figura 3 - Fotomicrografia, mostrando os arcos ciclóides superpostos à mucosa do intestino delgado, para estimativa da área de superfície da mucosa, corada com HE, em 40 aumentos

O presente estudo foi aprovado pela Comissão de Ética em Pesquisa do Grupo de Pesquisa e Pós-Graduação do Hospital de Clínicas de Porto Alegre.

\section{Resultados}

A média de idade dos pacientes deste estudo foi de 1 ano e 5 meses ( \pm 9 meses), 50 deles (77\%) tinham menos de 24 meses, havendo predomínio de brancos. A duração média da diarréia foi de 5,3 $( \pm 5,4)$ meses. Não houve relação entre o tempo de duração da diarréia e o estado nutricional. A avaliação pelos escores para duas categorias é a que se segue: $\mathrm{z}$ P/I $=29$ eutróficos e 36 desnutridos; z P/E $=41$ eutróficos e 24 desnutridos; z E/I $=45$ eutróficos e 20 desnutridos. A avaliação pelos escores para três categorias mostrou: $\mathrm{z} \mathrm{P} / \mathrm{I}=17$ eutróficos, $12 \mathrm{com}$ risco nutricional (risco nutricional) e 36 desnutridos; z P/E $=22$ eutróficos, 19 risco nutricional e 24 desnutridos; $z$ E/I: 28 eutróficos, 17 risco nutricional e 20 desnutridos. Cinco pacientes apresentavam edema nutricional. $\mathrm{O}$ valor médio para as variáveis estudadas, com aumento de 100 vezes, considerando-se todos os pacientes do estudo anterior ${ }^{16} \mathrm{e}$ do atual, está descrito na Tabela 1 . O valor médio para as variáveis estudadas em 500 aumentos, considerando-se os 65 pacientes, foi altura do enterócito: $28,7 \pm 4 \mu \mathrm{m}$; altura do núcleo: $8,1 \pm 1 \mu \mathrm{m}$; altura do bordo em escova: $1,9 \mu \mathrm{m} \pm 0,3 \mu \mathrm{m}$.

Tabela 1 - Comparação das características da mucosa intestinal através de morfometria com régua micrométrica

\begin{tabular}{lcc}
\hline Variável & $\begin{array}{c}\text { Primeiro estudo* } \\
\text { (85 pacientes) }\end{array}$ & $\begin{array}{c}\text { Estudo atual } \\
\text { (65 pacientes) }\end{array}$ \\
\hline Espessura total da mucosa & $485,1 \pm 111,8 \mu \mathrm{m}$ & $491,7 \pm 80,8 \mu \mathrm{m}$ \\
Altura das vilosidades & $268,3 \pm 87,5 \mu \mathrm{m}$ & $286,6 \pm 62,9 \mu \mathrm{m}$ \\
Profundidade das criptas & $112,9 \pm 33,8 \mu \mathrm{m}$ & $103,9 \pm 16,8 \mu \mathrm{m}$ \\
Espessura da mucosa & $210,6 \pm 73,2 \mu \mathrm{m}$ & $205,5 \pm 49,1 \mu \mathrm{m}$ \\
Relação vilo/cripta & $2,7 \pm 1$ & $2,8 \pm 0,7$ \\
\hline
\end{tabular}

* Referência 18. 
Utilizando-se o teste $t$ de Student, a análise morfométrica revelou que, quando os pacientes foram divididos em duas categorias de estado nutricional, segundo os escores z para P/I, P/E e E/I, não houve diferença estatisticamente significante entre as variáveis altura dos vilos, profundidade das criptas, espessura da mucosa e espessura total da mucosa e relação vilo/cripta, realizada em 62 fragmentos. Quando os pacientes foram divididos em três categorias de estado nutricional, a análise morfométrica digitalizada mostrou diferença estatisticamente significante para a relação vilo/cripta entre eutróficos e com risco nutricional, e entre eutróficos e desnutridos. Entretanto, não houve diferença entre os desnutridos leves e desnutridos moderados e graves. A relação vilo/cripta foi maior nos eutróficos.

Em nosso estudo anterior ${ }^{16}$, a análise realizada através do coeficiente de correlação de Spearman mostrou correlação positiva entre a altura dos vilos e o índice $\mathrm{P} / \mathrm{I}$, espessura total da mucosa e os índices P/I e P/E e entre a relação vilo/cripta e os índices P/I e P/E, obtendo-se valores menores nas crianças mais desnutridas. Em relação às variáveis altura do enterócito, altura do núcleo e do bordo em escova, avaliadas nos 65 fragmentos, levando-se em conta a classi- ficação de desnutrição por P/I, quando utilizamos o teste $t$, a característica que apresentou maior diferença entre os grupos eutrófico e desnutrido foi a altura do enterócito (eutróficos: 29,8 $\mu \mathrm{m}$, desnutridos: 27,9 $\mu \mathrm{m}$ ), o mesmo acontecendo ao se observar a classificação por P/E (eutróficos: 29,4 $\mu \mathrm{m}$, desnutridos: 27,6 $\mu \mathrm{m}$ ). Apesar disso, nenhuma das diferenças obtidas atingiu significância estatística.

No entanto, quando utilizamos o coeficiente de correlação de Pearson, para avaliar as correlações entre as diversas características da morfometria digital e os escores z, observou-se uma clara associação entre a altura do enterócito e os escores z P/I, P/E; entre a altura do núcleo e o escore z P/I, e entre a altura do bordo em escova e o escore z P/I, embora a força desta associação tenha sido de magnitude pequena a, no máximo, moderada. A Tabela 2 mostra a matriz de correlações, apresentando coeficientes de correlação linear de Pearson e significância estatística para características de morfometria digital versus avaliação do estado nutricional.

A avaliação estereológica, através de arcos ciclóides, realizada em 62 fragmentos, não mostrou resultados estatisticamente significantes em relação ao estado nutricional.

Tabela 2 - Matriz de correlações, apresentando coeficientes de correlação linear de Pearson e significância estatística para características de morfometria digital versus avaliação do estado nutricional

\begin{tabular}{|c|c|c|c|}
\hline \multirow[t]{2}{*}{ Variável } & \multicolumn{3}{|c|}{ Classificação } \\
\hline & $\begin{array}{l}\text { Peso/Idade } \\
\text { (escore z) }\end{array}$ & $\begin{array}{l}\text { Peso/Estatura } \\
\quad(\text { escore } z)\end{array}$ & $\begin{array}{l}\text { Estatura/Idade } \\
\quad(\text { escore } z)\end{array}$ \\
\hline $\begin{array}{l}\text { Altura dos vilos }-\mu \mathrm{m} \\
\text { aumento de } 100 X, n=62\end{array}$ & $\begin{array}{c}0,06 \\
\mathrm{p}=0,631\end{array}$ & $\begin{array}{c}0,13 \\
\mathrm{p}=0,309\end{array}$ & $\begin{array}{c}-0,01 \\
p=0,924\end{array}$ \\
\hline $\begin{array}{l}\text { Profundidade da cripta, } \mu \mathrm{m} \\
\text { aumento de } 100 \mathrm{X}, \mathrm{n}=62\end{array}$ & $\begin{array}{c}-0,03 \\
\mathrm{p}=0,803\end{array}$ & $\begin{array}{c}0,04 \\
p=0,783\end{array}$ & $\begin{array}{c}0,02 \\
p=0,858\end{array}$ \\
\hline $\begin{array}{l}\text { Espessura da mucosa, } \mu \mathrm{m} \\
\text { aumento de } 100 X, \quad n=62\end{array}$ & $\begin{array}{c}-0,15 \\
p=0,231\end{array}$ & $\begin{array}{c}0,02 \\
p=0,855\end{array}$ & $\begin{array}{c}-0,20 \\
p=0,125\end{array}$ \\
\hline $\begin{array}{l}\text { Espessura total da mucosa, } \mu \mathrm{m} \\
\text { aumento de } 100 \mathrm{X}, \mathrm{n}=62\end{array}$ & $\begin{array}{c}0,08 \\
p=0,551\end{array}$ & $\begin{array}{c}0,24 \\
p=0,060\end{array}$ & $\begin{array}{c}-0,06 \\
p=0,638\end{array}$ \\
\hline $\begin{array}{l}\text { Relação vilo/cripta, } \mu \mathrm{m} \\
\text { aumento de } 100 \mathrm{X}, \mathrm{n}=62\end{array}$ & $\begin{array}{c}0,13 \\
\mathrm{p}=0,314\end{array}$ & $\begin{array}{c}0,13 \\
\mathrm{p}=0,307\end{array}$ & $\begin{array}{c}-0,22 \\
p=0,867\end{array}$ \\
\hline $\begin{array}{l}\text { Superfície/volume } \\
\text { aumento de } 40 \mathrm{X}, \mathrm{n}=62\end{array}$ & $\begin{array}{c}-0,02 \\
\mathrm{p}=0,871\end{array}$ & $\begin{array}{c}0,19 \\
p=0,128\end{array}$ & $\begin{array}{c}-0,14 \\
p=0,281\end{array}$ \\
\hline $\begin{array}{l}\text { Altura do enterócito, } \mu \mathrm{m} \\
\text { aumento de } 500 X, n=65\end{array}$ & $\begin{array}{c}0,25^{*} \\
\mathrm{p}=0,038\end{array}$ & $\begin{array}{c}0,29 * \\
\mathrm{p}=0,019\end{array}$ & $\begin{array}{c}0,16 \\
p=0,179\end{array}$ \\
\hline $\begin{array}{l}\text { Altura do núcleo, } \mu \mathrm{m} \\
\text { aumento de } 500 X, n=65\end{array}$ & $\begin{array}{c}0,24^{*} \\
\mathrm{p}=0,054\end{array}$ & $\begin{array}{c}0,16 \\
p=0,188\end{array}$ & $\begin{array}{c}0,23 \\
p=0,063\end{array}$ \\
\hline $\begin{array}{l}\text { Altura do bordo em escova, } \mu \mathrm{m} \\
\text { aumento de } 500 \mathrm{X}, \mathrm{n}=65\end{array}$ & $\begin{array}{c}0,26^{*} \\
\mathrm{p}=0,032\end{array}$ & $\begin{array}{c}0,27 * \\
\mathrm{p}=0,030\end{array}$ & $\begin{array}{c}0,23 \\
p=0,062\end{array}$ \\
\hline
\end{tabular}

\footnotetext{
${ }^{*}$ Resultados estatisticamente significativos.
} 


\section{Discussão}

A diarréia persistente ocorre com mais freqüência durante os dois primeiros anos de vida ${ }^{20}$. Entre os pacientes deste estudo, 77\% tinham menos de dois anos de idade, confirmando a vulnerabilidade deste grupo etário para a maior prevalência de diarréia. Para Lentze ${ }^{20}$, em crianças desnutridas, às vezes, é difícil distinguir o que veio antes, se a diarréia ou a desnutrição.

Embora se saiba que os nutrientes luminais são essenciais para a integridade da mucosa intestinal, o papel da desnutrição na patogênese da má absorção e da enteropatia intestinal ainda é controverso. Esteatorréia e atrofia vilositária têm sido descritas em crianças com kwashiorkor e marasmo. Os graus mais leves de desnutrição não parecem ter maior impacto sobre a estrutura e a função da mucosa intestinal e, provavelmente, não explicam as alterações encontradas na arquitetura mucosa comumente vista nos trópicos ${ }^{21}$. As alterações descritas nos pacientes com diarréia protraída, desnutridos ou com enteropatia tropical, referem-se especialmente a alterações na morfologia da mucosa, na área de superfície da mucosa e nos enterócitos. Kallas et al. ${ }^{22}$, ao compararem crianças com diarréia por Escherichia coli enteropatogênica clássica com aquelas com enteropatia ambiental, observaram maior valor da zona críptica naquelas com enteropatia ambiental. $\mathrm{Na} \mathrm{Ve}-$ nezuela, Romer et al. ${ }^{23}$, ao estudarem a mucosa do intestino delgado de 24 crianças com diarréia com graus variados de desnutrição, agrupadas de acordo com a classificação de Gomez, não observaram correlação entre as alterações morfológicas e o grau de desnutrição. Ferreira e Fagundes $\mathrm{Neto}^{24}$, em São Paulo, encontraram, na mucosa intestinal de crianças com diarréia protraída, alterações de intensidade variada, não relacionadas ao estado nutricional das mesmas. Sullivan ${ }^{15}$, ao avaliar a mucosa jejunal do intestino delgado de crianças desnutridas (P/E < 75\% do NCHS), encontrou um espectro de alterações, desde mucosa normal até mucosa semelhante àquela observada nos portadores de doença celíaca. Observou ainda, em 29 delas, marcada hipertrofia de criptas, com elevada população de linfócitos intra-epiteliais. Em nosso estudo anterior ${ }^{16}$, encontramos associação positiva entre os escores z P/I e z P/E, em ordem decrescente, e as medidas da altura dos vilos, da espessura total da mucosa e da relação vilo/cripta, que foram menores nos mais desnutridos. A profundidade das criptas, no entanto, não se mostrou diferente entre os grupos. No presente estudo, que englobou 65 daquelas crianças, acrescentamos a avaliação nutricional, relacionada ao risco nutricional, e encontramos associação positiva para a relação vilo/cripta entre eutróficos e com risco nutricional e eutróficos e desnutridos, sendo de menor valor nos desnutridos. A diferença constatada entre os dois estudos na morfometria por régua micrométrica, provavelmente decorre da retirada de 20 pacientes, que incluiu aqueles maiores de cinco anos e aqueles cujos novos fragmentos tiveram menos de seis vilos e seis criptas, para análise morfométrica.
Com relação ao estudo dos enterócitos, ao medir a altura destas células em 19 crianças controles sem diarréia $(32,3 \pm 3,8 \mu \mathrm{m})$ e $23 \mathrm{com}$ diarréia persistente $(31,5 \pm$ $5,5 \mu \mathrm{m})$, sem mencionar o estado nutricional, Penna e cols. ${ }^{25}$ não detectaram diferença entre os grupos. No entanto, a comparação entre 24 com histologia "normal" e 18 com atrofia vilosa parcial $(34,1 \pm 3,4 \mu \mathrm{m}$ e $28,9 \pm 4,7 \mu \mathrm{m}$, respectivamente) mostrou diferença estatisticamente significante entre os grupos. Bhan e cols. ${ }^{10}$ avaliaram a altura do enterócito de diferentes grupos de crianças: eutróficas, com diarréia protraída de diferentes etiologias, com doença celíaca e desnutridas graves. Os valores da altura dos enterócito foram maiores nas eutróficas $(31 \pm 2,7 \mu \mathrm{m}) \mathrm{e}$, em ordem decrescente, naquelas com desnutrição grave $(25,3 \pm$ $1,7 \mu \mathrm{m})$; nas portadoras de E. coli enteropatogênica (20,9 $\pm 2,6 \mu \mathrm{m})$ e naquelas com doença celíaca não tratada (15,5 $\pm 2,6 \mu \mathrm{m})$. Bahn e cols. ${ }^{10}$, como na presente pesquisa, constataram maiores valores de altura do enterócito em eutróficos, quando comparados com desnutridos graves.

No presente trabalho, os valores encontrados assemelham-se aos encontrados por Penna e cols. ${ }^{25}$ naqueles com atrofia vilosa parcial, bem como àqueles detectados por Wood e colaboradores ${ }^{26}$ que, ao avaliarem pacientes adultos, observaram diferença estatisticamente significante entre pacientes brancos ingleses $(30,2 \mu \mathrm{m}) \mathrm{e}$ imigrantes indianos $(28,3 \pm 2,7 \mu \mathrm{m})$ e afro-caribenhos $(27,2 \pm 2,7 \mu \mathrm{m})$. Estes autores propõem que tais achados “...refletem $a$ morfologia 'normal' de pacientes imigrantes, determinada por fatores ambientais".

Entre os pacientes deste estudo, através do teste de Student, nas classificações por z P/I e z P/E, encontrou-se maior diferença entre eutróficos e desnutridos para o tamanho do enterócito, sem, todavia, atingir significância estatística. Entretanto, a análise através do coeficiente de correlação linear de Spearman revelou diferença estatisticamente significativa entre a altura do enterócito, a altura do núcleo e do bordo em escova e o índice P/I e altura do enterócito e do bordo em escova e o índice P/E. Há uma tendência de diminuição da altura destas estruturas à medida que aumenta o grau de desnutrição. Tal achado sugere que a desnutrição per se possa estar associada à diminuição da altura do enterócito. Constatou-se, ainda, redução nas medidas do núcleo e do bordo em escova do enterócito nos mais desnutridos.

A análise estereológica para medida da superfície absortiva intestinal, realizada no estudo atual através dos arcos ciclóides, não mostrou correlação positiva com o estado nutricional. Ribeiro e cols. ${ }^{27}$, no entanto, em estudo experimental do epitélio do intestino delgado, em ratos com desnutrição protéico-energética, constataram redução da superfície absortiva jejunal onde não havia alteração evidente da altura das vilosidades. Concluíram que a desnutrição pode afetar a função intestinal através da diminuição da superfície absortiva, sem alteração estrutural aparente. Wood, Gearty e Cooper ${ }^{26}$, como em nossa pesquisa, também não encontraram diferença estatisticamente signifi- 
cante na relação superfície/volume, ao estudarem pacientes adultos indianos, afro-caribenhos e ingleses. Estes autores sugerem que a semelhança da relação área de superfície/ volume entre estes grupamentos pode ser explicada pela menor espessura da mucosa do intestino delgado dos pacientes imigrantes.

Não encontramos, na literatura revisada, estudos de avaliação estereológica da mucosa intestinal em pacientes pediátricos.

Em conclusão, constatou-se, como no estudo anterior, que as correlações encontradas sempre estiveram relacionadas ao peso dos pacientes. Assim, as associações mais importantes detectadas foram entre o estado nutricional e a morfologia do enterócito. Embora estas associações tenham sido de magnitude fraca a moderada, há uma tendência à diminuição do tamanho do enterócito, de seu núcleo e seu bordo em escova à medida que aumenta o grau de desnutrição. A importância do estudo do enterócito da mucosa do intestino delgado reside no fato de que ele tem um relevante papel na proteção imunológica da referida mucosa ${ }^{28}$. As interações entre as alterações morfoestruturais e imunológicas da mucosa do intestino delgado na desnutrição protéico-energética necessitam ser mais estudadas, objetivando-se melhorar as condições de tratamento da criança desnutrida ${ }^{29}$.

\section{Agradecimento}

Agradecemos ao Dr. João Carlos Prolla, chefe da Unidade de Citologia do Hospital de Clínicas de Porto Alegre, pelo uso do microscópio acoplado ao computador para a realização desta pesquisa.

\section{Referências bibliográficas}

1. Organización Panamericana de la Salud. Brasil. In: Las Condiciones de Salud en las Americas. Washington: Organización Mundial de la Salud; 1990.

2. Pelletier DL, Frongillo EA, Schroeder DG. The effects of malnutrition on child mortality in developing countries. Bull WHO 1995; 73:443.

3. Sullivan PB. Studies of the small intestine in persistent diarrhea and malnutrition: the Gambian experience. J Pediatr Gastroenterol Nutr 2002;34 Suppl 1:11-3.

4. Magalhães AF, Trevisan MA, Pereira AS. Jejunal biopsies in protein-calorie malnutrition and intestinal parasitic infestation in Brazil. Am J Gastroenterol 1975;64:472-7.

5. Brewster DR, Manary MJ, Menzies IS, O'Loughlin EV, Henry RL. Intestinal permeability in kwashiorkor. Arch Dis Child 1997;76:236-41.

6. Hamilton PW, Allen DC. Morphometry in histopathology. J Pathol 1995; 175:369-79.

7. Rahman SM, Itakura H. Morphometry in histopathology. An image analysis workstation for pathology laboratory. Anal Quant Cytol Histol 1996;18(6):471-80.

8. Stanfield JP, Hutt MS, Tunnicliffe R. Intestinal biopsy in kwashiorkor. Lancet 1965;2:519-23.
9. Brunser O, Castillo C, Araya M. Fine structure of the small intestinal mucosa in infantile marasmic malnutrition. Gastroenterology 1976;70:495-507.

10. Bhan MK, Khoshoo V, Phillips AD, Smith JA, Mathur M. The enterocyte height \& number in children with protracted diarrhea. Indian J Med Res 1988;88:525-9.

11. Kelly P, Davies SE, Mandanda B, Veitch A, McPhail G, Zulu I, et al. Enteropathy in Zambian with HIV related diarrhea: regression modeling of potential determinants of mucosal damage. Gut 1997;41:811-6.

12. Burman D. The jejunal mucosa in kwashiorkor. Arch Dis Child 1965;40:526-31.

13. Barbieri D. Mucosa jejunal na má nutrição protéica grave da criança [tese de doutorado]. São Paulo (SP): Universidade de São Paulo; 1971.

14. Martins MCV, Lima FMLS, Patrício FRS, Toledo MRF, Machado NL, Fagundes-Neto U. Enteropatia ambiental assintomática: alterações funcionais e morfológicas na mucosa jejunal decorrentes de ambiente desfavorável. J Pediatr (Rio J) 1991;67:87-91.

15. Sullivan PB, Marsh MN, Mirakian R, Hill SM, Milla PJ, Neale G. Chronic diarrhea and malnutrition - histology of the small intestinal lesion. J Pediatr Gastroenterol Nutr 1991;12:195-203.

16. Pires AL, Silveira TR, Scholl JG. Relationship between nutritional status and histologic findings in small bowel mucosa of children presenting with diarrhea of more than 14 days' duration. J Trop Pediatr 1999;45:302-4.

17. Rasband W. Scion Image Beta 2 version on line. National Institutes of Health, modified by Scion Corporation Frederick; 1997 [site na Internet]. Disponível: www.scioncorp.com. Acessado: 15 de setembro de 1998.

18. National Center for Health Statistics. Growth Curves for Children: Birth - 18 years. Hyattsville: U.S. Department of Health, Education and Welfare; 1977.

19. Altman DG. Practical statistics for medical research. London: Chapman \& Hall/CRC; 1991

20. Lentze MJ. Persistent diarrhea. In: Walker A, Durie PR, Hamilton JR, Walker-Smith JB, Watkins JB, editores. Pediatric Gastrointestinal Disease: Pathophysiology, Diagnosis, Management. Ontario: BC Decker Inc; 2000.p.39-45.

21. Farthing MJG. Tropical malabsorption and tropical diarrhea. In: Feldman M, Friedman LS, Sleisenger MH, editores. Gastrointestinal and Liver Disease. New York: W.B. Saunders; 2002.p.1842-53.

22. Kallas MRE, Patrício FRS, Fagundes-Neto U. Morfometria do intestino delgado em crianças com diarréia por Escherichia coli enteropatogênica clássica e enteropatia ambiental assintomática. Rev Ass Med Brasil 1995;41(3):162-6.

23. Romer H, Urbach R, Gomez MA, Lopez A, Perozo-Ruggeri G, Vegas ME. Moderate and severe protein malnutrition in childhood: effects on jejunal mucosal morphology and dissacharidases activities. J Pediatr Gastroenterol Nutr1983;2:459-64.

24. Ferreira VC, Fagundes-Neto U. Diarréia protraída: tratamento dietético e intolerância alimentar. J Pediatr (Rio J) 1988;64: 375-84.

25. Penna FJ, Hill ID, Kingston D, Robertson K, Slavin G, Shiner M. Jejunal morphometry in children with and without gut symptoms and in normal adults. J Clin Pathol 1981;34:386-92.

26. Wood GM, Gearty JC, Cooper BT. Small bowel morphology in British Indian and Afro-Caribbean subjects: evidence of tropical enteropathy. Gut 1991;32:256-9.

27. da Costa Ribeiro H Jr., Teichberg S, McGarvey E, Lifshitz F. Quantitative alterations in the structural development of jejunal absorptive epithelial cells and their subcellular organelles in protein-energy malnourished rats: a stereologic analysis. Gastroenterology 1987;93:1381-92. 
28. Madi K, Zaltman C, Takiya CM. Arquitetura da mucosa intestinal e sua plasticidade. In: Elia CCS, Souza HSP. Imunologia da Mucosa Intestinal. São Paulo: Atheneu; 2000.p.11-39.

29. Fogaça HS. Desnutrição. In: Elia CCS, Souza HSP. Imunologia da Mucosa Intestinal. São Paulo: Atheneu; 2000.p.159-63.
Endereço para correspondência:

Dra. Ana Luiza Guedes Pires

Rua Dr. Tauphick Saadi, 357 - ap. 602

CEP 90470-040 - Porto Alegre, RS

Tel.: (51) 3331.2657 - Fax: (51) 3333.3000

E-mail: piresacj@via-rs.net 